\title{
11. DOS NUEVAS CITAS DE LEMNACEAE PARA LA FLORA IBÉRICA
}

\author{
Antonio GALÁN DE MERA, Carlos AEDO, \\ Santiago CASTROVIEJO y Óscar SÁNCHEZ PEDRAJA
}

Two new records for Lemnaceae in the Iberian Peninsula

Palabras clave. Lemnaceae, Península Ibérica.

Key words. Lemnaceae, Iberian Peninsula.

Continuando con la revisión de las Lemnáceas para el volumen XVIII de Flora iberica damos a conocer, otra vez [cf. Galán de Mera \& Castroviejo, Acta Bot. Malacitana 30: 248-249 (2005)], novedades corológicas en el género Lemna:

Lemna minuta Kunth in Humb., Bonpl. \& Kunth, Nov. Gen. Sp. 1: 372 (1815)

PORTUGAL : BEIRAALTA. pr. Pinhel, bebedero antiguo al borde de una carretera, $40^{\circ} 50^{\prime} 16^{\prime \prime} \mathrm{N}, 07^{\circ} 02^{\prime} 01^{\prime \prime} \mathrm{W}, 418 \mathrm{~m}, 10-\mathrm{VI}-$ 2006, C. Aedo 12838 (MA).

A la cita anterior de Douro Litoral [Galán de Mera \& Castroviejo, Acta Bot. Malacitana 30: 249 (2005)] añadimos ésta que amplía el área de esta especie en Portugal donde llega a ser abundante, pues sin ser herborizada, fue observada en otras localidades (v. gr. BEIRA ALTA: Mohínos de Aveia, en un arroyo con aguas remansadas, $40^{\circ} 42^{\prime} 01^{\prime}$ 'N, $07^{\circ} 12^{\prime} 01^{\prime \prime} \mathrm{W}, 550$ m, 10-VI-2006, C. Aedo).

Lemna valdiviana Phil. in Linnaea 33: 239 (1864)

ESPAÑA: CANTABRIA. Noja, hacia el puente de Barbijos, remansos de la ría,
30TVP5713, 28-VIII-1998, M. Lainz, G. Moreno Moral \& Ó. Sánchez Pedraja SP0562 (herb. Sánchez Pedraja 08217).

Las frondes 1,3-3 x 1,1-1,8 mm, elípticas y con un solo nervio visible que acaba en un pequeño mucrón, no ofrecen dudas de que estas plantas -citadas como $L$. minuta [Aedo et al., Bol. Ci. Naturaleza R.I.D.E.A. 46: 103 (2001)]- presentan los caracteres de L. valdiviana.

Se trata de la primera cita de esta especie para la flora española.

Aceptado para su publicación en octubre de 2006

Dirección de los autores: C. AEDO y S. CASTROVIEJO: Real Jardín Botánico, Plaza de Murillo 2, E-28014 Madrid; A. GALÁN DE MERA: Departamento de CC Ambientales y Recursos Naturales (Botánica), Facultad de Farmacia, Universidad San Pablo-CEU, apartado 67, E-28660 Boadilla del Monte, Madrid (agalmer@ceu.es); Ó. SÁNCHEZ PEDRAJA: E1 Mercadillo 12, E-39722 Liérganes, Cantabria. 